Check for updates

The BMJ

Cite this as: $B M J 2021 ; 372: n 23$ http://dx.doi.org/10.1136/bmj.n23 Published: 05 January 2021

\title{
Covid-19: UK study aims to understand effects on ethnic minority healthcare workers
}

\section{Elisabeth Mahase}

A new study has launched in the UK to understand the impact of covid-19 on healthcare workers of different ethnic groups.

The UK-Reach study brings together researchers and clinicians with the General Medical Council, Nursing and Midwifery Council, royal colleges, and ethnic minority healthcare worker associations to investigate if, how, and why ethnicity affects clinical outcomes of covid-19 in healthcare workers. It will also look at the effects of the pandemic on the physical and mental health outcomes of staff.

Covid-19 has disproportionately affected people from ethnic minority groups, with many medical leaders warning that not enough is being done to protect these communities. ${ }^{1}$ In April 2020, data from the Intensive Care National Audit and Research Centre showed that one third (34\%) of patients admitted to intensive care with covid-19 were from an ethnic minority background. In June, it was reported that nearly two thirds $(63 \%)$ of healthcare workers who died after contracting the virus were from ethnic minority backgrounds. ${ }^{2}$

A review from the government's Race Disparity Unit said that most of the increased risk among people from ethnic minorities could be explained by factors such as occupation, where people live, household composition, and pre-existing health conditions. ${ }^{3}$ It said, however, that part of the excess risk remained unexplained in some groups such as black men, and more research was needed.

The research is being led by Manish Pareek, associate clinical professor in infectious diseases at the University of Leicester and honorary consultant in infectious diseases at Leicester Royal Infirmary. Speaking to The BMJ, Pareek said, "We're funded for a year initially, so there'll be some short term outcomes, but we hope that this will become a longer term study to try and understand whether people who have been working in a pandemic have had particular mental health problems.”

The researchers will link NHS datasets to understand who is being infected, who is ending up in intensive care, and who is dying. They are also currently recruiting healthcare workers who can take part by sharing information on their work behaviours, home behaviours, and insights into their mental and physical health. So far 6000 people have signed up, but the study aims to recruit 30 ooo healthcare workers in total. 4

"We hope to quantify who is at risk, because at the moment it's anecdotal," said Pareek. "We don't have a clear understanding of who the highest risk populations are. We're also interviewing staff to understand their experiences of working during the pandemic, because of the problems around structural racism and institutional racism. So that's going to come out in some of the qualitative work that we're doing."

If they can identify who is at high risk and why, Pareek said the government and NHS can then act to protect those people. "If we can tease that out why some groups are high risk, we can potentially prioritise vaccination, making sure that people who are at high risk are not necessarily being put into those high risk environments, and then perhaps preventing them from ever becoming infected," he explained.

The research team said they expected some initial findings early this year.

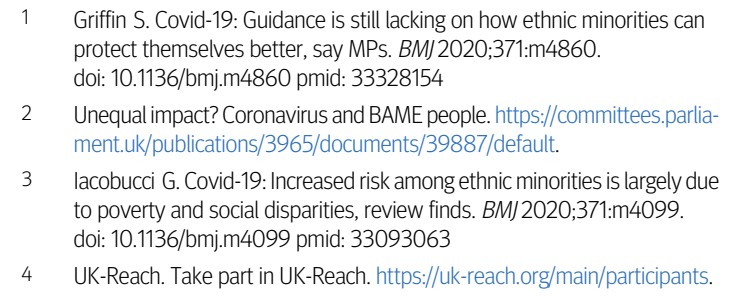

Griffin S. Covid-19: Guidance is still lacking on how ethnic minorities can protect themselves better, say MPs. BM/2020;371:m4860. doi: 10.1136/bmj.m4860 pmid: 33328154

2 Unequal impact? Coronavirus and BAME people. https://committees.parliament.uk/publications/3965/documents/39887/default.

3 lacobucci G. Covid-19: Increased risk among ethnic minorities is largely due to poverty and social disparities, review finds. BMJ2020;371:m4099. doi: 10.1136/bmj.m4099 pmid: 33093063

4 UK-Reach. Take part in UK-Reach. https://uk-reach.org/main/participants. 